\title{
RESIKO BEKERJA DI AREA RUMAH SAKIT
}

\author{
MEGA CERIA PURNAMA ZEBUA
}

Megaceria25@gmail.com

\begin{abstract}
ABSTRAK
Latar Belakang. Rumah Sakit merupakan tempat kerja serta tempat berkumpulnya orangorang sehat (petugas dan pengunjung) dan orang- orang sakit (pasien) sehingga rumah sakit merupakan tempat kerja yang mempunyai risiko tinggi terhadap penyakit akibat kerja maupun penyakit akibat kecelakaan kerja. Resiko kontak dengan agen penyakit menular, dengan darah dan cairan tubuh maupun tertusuk jarum, instrumen tajam yang dapat berperan sebagai tranmisi berbagai penyakit. Untuk alasan itu maka pekerja rumah sakit berkewajiban untuk menjalankan upaya pembinaan Keselamatan dan Kesehatan Kerja Rumah Sakit (K3RS). Yang bertujuan untuk terhindar dari adanya resiko kecelakan kerja. Tujuan: Untuk lebih memahami resiko yang dapat terjadi ketika bekerja di rumah sakit dan menerapkan K3RS untuk upaya pencegahan. Metode: Penelitian ini menggunakan jenis penelitian explanatory research. Kesimpulan: Banyak hal yang dapat terjadi saat melakukan pekerjaan, itu adalah resiko dari sebuah perkejaan. Resiko pasti selalu ada, yang baik maupun buruk. Dalam dunia keperawatan juga begitu banyak resiko, resiko terinfeksi. Maka ikuti SOP yang berlaku agar meminimalisir kecelakaan kerja.
\end{abstract}

Kata Kunci: kecelakan kerja, APD, Stres kerja 


\section{LATAR BELAKANG}

Rumah sakit merupakan sarana pelayanan kesehatan yang beragam dan memiliki permasalahan tenaga kerja yang mempunyai resiko terkena penyakit akibat kerja bahkan dapat mengancam keselamatan tenaga pekerja tersebut. Untuk alasan itu maka pekerja rumah sakit berkewajiban untuk menjalankan upaya pembinaan Keselamatan dan Kesehatan Kerja Rumah Sakit (K3RS). Yang bertujuan untuk terhindar dari adanya resiko kecelakan kerja.

Menurut data Depkes 2007, di Indonesia diketahui bahwa resiko bahaya yang dialami oleh pekerja di rumah sakit adalah HIV (0,3\%), resiko pajanan membrane mukosa $(1 \%)$, resiko pajanan kulit $(<1 \%)$ dan sisanya tertusuk jarum, low back paint akibat mengangkat beban melebihi batas, gangguan pernafasan, dermatitis dan hepatitis.

Dalam komponen pelayanan rumah sakit perawat adalah salah satu tenaga pelayanan kesehatan yang sangat beriko mengalami kecelakan kerja, dikarenakan perawat mendampingan pasien lebih lama dari komponen pelayanan lainnya. Dirumah sakit pasti banyak fasilitas pelayanan yang disediakan untuk menunjang profil sebuah rumah sakit. Dikarenakan fasilitas yang banyak maka banyak juga bentuk masalah k3 yang dialami. Semakin banyak fasilitas maka semakin banyak potensi bahaya yang dapat terjadi. Beberapa contoh bahaya ialah bahaya biologi seperti penularan penyakit HIV, Hepatitis, TBC. Bahaya radiasi sinar $X$-Ray, Bahaya Fisiki lingkungan kerja, benda tajam, terjatuh, kelelahan, stres, low back pain (Putri, Santoso, \& Rahayu, 2018).

Diinstalasi Kegawat Daruratan setiap saat ada kasus dari berbagai tingkat kegawatan yang membutuhkan perawatan segera. Perawat yang sebagai tenaga kerja yang pertama kali kontak dengan pasien harus selalu sigap untuk mencegah hal hal yang tidak diinginkan. Dengan berbagai macam kewajiban perawat dalam melakukan pelayanan maka perawat sering mengalami stres, stres adalah kondisi fisik dan psikologis yang disebabkan karena adaptasi seseorang pada lingkungannya. Stres bisa berasal dari lingkungan kerja, lingkungan tempat tinggal. Perawat juga memikirkan hal hal lain selain pekerjaan sebagai perawat, seperti mengurus rumah tangga jika perawat tersebut sudah berumah tangga, ataupun memikirkan pekerjaan pekerjaan rumah, orang tua.

Dengan stres yang dialami perawat dapat mengganggu pelayanan dirumah sakit, perawat jadi tidak fokus sehingga sangat beresiko mengalami kecelakan. Seperti saat memberikan obat dalam bentuk suntikan kepada pasien HIV bisa saja saat 
setelah melakukan suntikan dapat tertusuk ditangan perawat tersebut, sehingga beresiko tertular penyakit HIV. Dampak buruk lain yang dapat ditimbulkan jika seorang perawat mengalami stres ialah dapat mengganggu interaksi sosialnya, baik itu dengan rekan kerja, dokter ataupun pasien. Efektivitas kerja dapat pula menjadi terganggu karena pada umumnya apabila seseorang mengalami stres maka akan terjadi gangguan baik itu pada psikologisnya maupun keadaan fisiologisnya (Kasmarani, 2012).

\section{METODE}

Rancangan penugasaan kajian ini menggunakan buku teks, buku referensi, ebook, jurnal dengan menganalisa dan kajian bebas. Penelitian ini menggunakan jenis penelitian explanatory research. Penelitian eksplanatori ( explanatory research ) bersifat penjelasan dan bertujuan untuk menguji suatu teori atau hipotesis guna memperkuat atau bahkan menolak teori atau hipotesis hasil penelitian yang sudah ada.

\section{HASIL DAN PEMBAHASAN}

Rumah sakit merupakan tempat kerja serta tempat berkumpulnya orangorang sehat baik petugas, pengunjung dan orang-orang sakit (pasien) sehingga rumah sakit merupakan tempat kerja yang mempunyai risiko tinggi terhadap kesehatan maupun penyakit akibat kecelakaan kerja, dan juga karena kontak dengan agen penyakit menular, dengan darah dan cairan tubuh maupun tertusuk jarum, instrumen tajam yang dapat berperan sebagai tranmisi berbagai penyakit, seperti hepatitis B, HIV/AIDS, dan juga potensial sebagai media penularan penyakit yang lain.

Penularan infeksi yang terjadi pada perawat dapat disebabkan oleh tindakan perawat yang sering kontak dengan darah, jaringan, dan sekresi cairan yang masuk kedalam tubuh baik tertusuk jarum atau luka, percikan darah. Salah satu penyebabnya ialah bekerja tanpa menggunakan alat pelindung diri (APD). Ketidakpatuhan terhadap peraturan membuat diri sendiri celaka (Sudarmo, Helmi, \& Marlinae, 2016).

Perilaku kesehatan dan keselamatan kerja perawat di rumah sakit sangat penting, karena tindakan perawat sekecil apapun dapat menimbulkan risiko terhadap perawat dan pasien. Banyak penelitian yang menunjukan rendahnya kepatuhan terhadap penggunaan APD. Data hasil penelitian Aarabi et.al (2008) menyatakan hanya 33,9\% dari 250 tenaga medis yang patuh terhadap standar operasioanal prosedur penggunaan masker. Hasil penelitian Ganezak dan Szych (2007) mendeskripsikan hanya 5\% 
perawat yang peduli dan taat dalam mengunakan sarung tangan, masker, baju pelindung dan kaca mata pelindung secara rutin.

Namun dalam penelitian "Faktor Yang Mempengaruhi Perilaku Terhadap Kepatuhan Penggunaan Alat Pelindung Diri (Apd) Untuk Pencegahan Penyakit Akibat Kerja" oleh Sudarmo dkk tahun 2016, mengatakan bahwa ada beberapa faktor yang menyebabkan perawat tidak menggunakan APD seperti yang seharusnya. Faktor lingkungan yang terbiasa tidak menggunakan APD dapat mempengaruhi seseorang yang menggunakan APD, tersedia atau tidak tersediannya APD yang memadai juga mempengaruhi penggunaan APD, persediaan yang sedikit membuat tenaga kerja menggunakan APD dengan hemat.

Penyakit akibat kerja adalah penyakit yang disebabkan oleh pekerjaan dan lingkungan kerja. Faktor faktor resiko yang dapat menyebabkan terjadinya PAK ialah:

1. Golongan Fisik

- Kebisingan yang dapat mengakibatkan gangguan pendengaran.

- Radiasi yang dapat mengakibatkan kelainan darah dan kulit.
- Suhu udara yang tinggi dapat menyebabkan heat stroke dan suhu udara rendah yang mengakibatkan hypothermia.

- Pencahayaan yang rendah dapat mengakibatkan sakit mata dan dapat menimbulkan kecelakaan lainnya.

2. Golongan infeksi

- HIV/AIDS

3. Golongan Fisiologis

Dapat disebabkan oleh kesalahan kontruksi, mesin, sikap badan yang kurang baik, salah cara melakukan suatu pekerjaan yang dapat mengakibatkan kelelahan fisik bahkan lambat laun dapat menyebabkan perubahan fisik pada tubuh pekerja.

4. Golongan Mental

Dapat terjadi karena stres yang terjadi, stres yang diakibatkan oleh lingkungan kerja, keluarga, hubungan kerja yang tidak baik.

Pencegahan yang dapat dilakukan ialah: Peningkatan kesehatan (health promotion). Seperti penyuluhan tentang K3, 
pengembangan kepribadian yang baik, lingkungan kerja yang memadai. Peningkatan kesadaran perawat dalam menggunakan APD, menetapkan SOP dengan tegas dan melakukan evaluasi, menyediakan dan merawat APD yang tersedia agar saat digunakan tidak terdapat kerusakan pada APD (Salawati, 2015).

\section{KESIMPULAN}

Banyak hal yang dapat terjadi saat melakukan pekerjaan, itu adalah resiko dari sebuah perkejaan. Resiko pasti selalu ada, yang baik maupun buruk. Dalam dunia keperawatan juga begitu banyak resiko, resiko terinfeksi, resiko stres kerja. Namun resiko tersebut dapat diminimalisir dengan mengikuti standar yang ada dirumah sakit, mengikuti SOP, mengikuti upaya K3RS. Saat mengikuti hal tersebut maka kecelakan kerja dapat di minimalisir.

\section{DAFTAR PUSTAKA}

Cahyono, A. (2015). Hubungan

Karakteristik dan Tingkat

Pengetahuan Perawat Terhadap

Pengelolaan Keselamatan Pasien di Rumah Sakit.

Dewi, Y. A. (2017). Faktor-Faktor yang mempengaruhi penerapan sasaran keselamatan pasien pada perawat diruang rawat inap kelas I,II,II

RSUD Dr.Soedirman Kebumen.

Isnaini, N. (2014). Pengalaman perawat pelaksana dalam menerapkan keselamatan pasien. Jurnal Manajemen Keperawatan.

Kasmarani, M. K. (2012). PENGARUH BEBAN KERJA FISIK DAN MENTAL TERHADAP STRES KERJA PADA PERAWAT DI INSTALASI GAWAT DARURAT RSUD CIANJUR. Jurnal Kesehatan Masyarakat, 767-776.

Laputi, W. I. (2015). Tingkat Stres Mahasiswa Pendidikan Profesi Ners Program Studi Ilmu Keperawatan Unieversitas Muhammadiyah Yogyakarta.

Lombu, I. S. (2018). Hubungan Tingkat Stres Dengan Strategi Koping Mahasiswa Reguler Profesi Ners Di Fakultas Keperawatan Universitas Sumatera Utara.

Nazirah, R. (2017). Perilaku Perawat dalam Penerapan Manajemen Kesehatan dan Keselamatan.

Putri, S., Santoso, \& Rahayu, E. P. (2018). Pelaksanaan keselamatan dan kesehatan kerja terhadap kejadian kecelakaan kerja perawat rumah sakit. Jurnal Endurances. 
Salawati, L. (2015). PENYAKIT AKIBAT

KERJA DAN PENCEGAHAN.

Jurnal Kedokteran Syiah Kuala.

Simamora, R. H. (2017). A strengthening of role of health cadres in BTAPositive Tuberculosis (TB) case invention through education with module development and video approaches in Medan Padang bulan Comunity Health Center, North Sumatera Indonesia. International Journal Of Applied Engineering Reseach.

Sudarmo, Helmi, Z. N., \& Marlinae, L. (2016). FAKTOR YANG MEMPENGARUHI PERILAKU TERHADAP KEPATUHAN

PENGGUNAAN ALAT

PELINDUNG DIRI (APD)

UNTUK PENCEGAHAN

PENYAKIT AKIBAT KERJA.

Jurnal Berkala Kesehatan. 